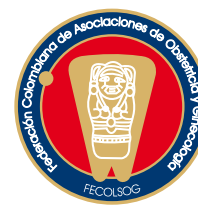

EDITORIAL

\title{
TRAS LA DETECCIÓN Y PREVENCIÓN DE LA VIOLENCIA CONTRA LA MUJER: EL COMPROMISO DE LA GINECOLOGÍA Y LA OBSTETRICIA
}

\author{
The commitment of obstetrics and gynecology: \\ following the detection of violence against women \\ and its prevention
}

María Mercedes Lafaurie-Villamil*

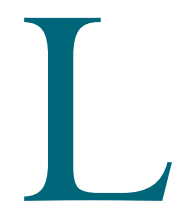

a violencia de género y en particular aquella ejercida contra la mujer es un problema multifactorial muy propio de estructuras sociales y culturales de orden patriarcal en las cuales impera el dominio masculino, incluso por la fuerza, y se presentan desequilibrios en lo relativo a la igualdad y equidad entre mujeres y hombres. Es más frecuente en contextos en los cuales se presentan carencias y desniveles en los patrones de desarrollo social.

Lamentablemente, América Latina muestra cifras de violencia contra la mujer de inmensas magnitudes, siendo Colombia un país donde esta realidad se presenta en una dolorosa y preocupante proporción. Como miembro de las Naciones Unidas, nuestro país se ha comprometido, entre otras, con la Plataforma de Beijing (1995) y con el logro de los Objetivos del Milenio, dentro de los cuales está la erradicación de esta realidad que no solo afecta los derechos humanos de las mujeres sino que constituye una problemática estructural de salud pública que incide en el devenir

* Psicóloga de la Universidad Javeriana, Profesora Asociada de la Universidad del Bosque. Investigadora en asuntos de género y salud sexual y reproductiva de la Fundación Educación para la Salud Reproductiva, ESAR. Bogotá, Colombia. Correo electrónico: mariamlafaurie@yahoo.com de la sociedad, de la familia y de todas las instancias de relación entre las personas, disminuyendo las posibilidades de avanzar en pos de una calidad de vida y de un equilibrio social.

Como bien conocemos la violencia doméstica de tipo físico y psicológico, la mayoría de las veces perpetrada por su pareja, es una de las formas más frecuentes de la violencia ejercida contra la mujer y, aunada a la violencia sexual, hace parte de aquellas expresiones de sometimiento que por presentarse en el ámbito privado son con frecuencia invisibles para la sociedad. Aspectos culturales muy arraigados perpetúan esta forma de violencia, la cual se presenta en un gran número de hogares colombianos cuando, de acuerdo con la Encuesta Nacional de Demografía y Salud de Profamilia (2005), un 39\% de las mujeres, alguna vez unidas manifiestan haber sido víctimas de violencia física por parte de sus parejas al menos una vez.

Frente a esta situación, requerimos contar con rutas de acceso a la población que nos permitan profundizar en las formas como se presenta este tipo de violencia, en sus antecedentes y en sus consecuencias, con el fin de poder establecer estrategias adecuadas para enfrentarla. Es por ello que los esfuerzos tendientes a dimensionar, a clarificar y a comprender la violencia contra la mujer que se ejerce en el ámbito 
doméstico, representan un aporte altamente significativo para el bienestar de las mujeres en nuestro país.

Se han logrado avances que permiten reconocer, cada vez en mayor medida, las coordenadas implicadas en la presentación de este fenómeno. Suelen ser las mujeres más pobres y con menos recursos económicos, educativos y sociales las de mayor riesgo, aunque se conoce que este tipo de violencia permea todos los estratos sociales.

Sin duda, el campo de la salud de la mujer representa un contexto de especial importancia para la detección de la violencia doméstica y sexual. La vulnerabilidad femenina en estos niveles puede ser especialmente palpable en el ámbito de la ginecología y la obstetricia, en el cual, además de que se tiene un contacto permanente y estrecho con las mujeres, se cuenta con espacios propicios y con medios para acceder a las evidencias asociadas a esta forma de maltrato, al igual que para realizar acercamientos a las percepciones que poseen y a las formas de sentir los hechos de violencia por parte de ellas.

El compromiso de las y los profesionales de la ginecología y la obstetricia con la detección y prevención de la violencia contra la mujer, es cada vez mayor en el mundo. Felizmente, en Colombia, en el campo de la investigación se abren caminos promisorios dentro de este ámbito profesional, donde se conoce, entre otras, que existen estrechas relaciones entre los hechos de violencia y los procesos reproductivos. Abortos provocados y motivados por maltrato son frecuentes en nuestro medio, así como las problemáticas asociadas al preparto, parto y posparto.

Es de celebrar el esfuerzo que están haciendo con respecto a la detección de la violencia conyugal las y los investigadores de grupos interdisciplinarios, desde los servicios de ginecología y obstetricia en el nivel hospitalario, y son bienvenidos en nuestro país los aportes realizados en el campo de la prevalencia de esta problemática, como aquellos derivados del trabajo realizado en el Instituto Materno Infantil de Bogotá por los investigadores Sandra Milena López, Pío Iván Gómez e Ingrid Arévalo, el cual se publica en esta entrega, cuyos resultados han sido presentados y debatidos en el contexto internacional y cuyos autores merecen un reconocimiento especial, atendiendo a la complejidad de esta problemática, a la importancia de los aportes de este trabajo y al recorrido, que de seguro ha sido necesario realizar, para que este estudio llegase a feliz término, dada la sensibilidad del tema abordado. 